\title{
Influence of Steel Scrap in the Charge on the Properties of Gray Cast Iron
}

\author{
Peter FUTÁŠ, ${ }^{1)}$ Alena PRIBULOVÁ, ${ }^{1)}$ Gabriel FEDORKO ${ }^{2 *}$ and Vieroslav MOLNÁR ${ }^{21}$ \\ 1) Faculty of Metallurgy, Technical University of Kosice, Letna 9, 04200 Kosice, Slovak Republic. \\ 2) Technical University of Kosice, Letna 9, 04200 Kosice, Slovak Republic.
}

(Received on July 4, 2016; accepted on October 11, 2016)

\begin{abstract}
In metallurgy, there are many factors influencing the quality of gray iron. These are especially the charge material, chemical composition (content of $\mathrm{C}, \mathrm{Si}, \mathrm{Mn}, \mathrm{P}, \mathrm{S}$ ), metallurgical treatment until the final casting process. Charge materials, in particular the steel scrap ratio exerts notable effect on the quality of gray cast iron, which is increasingly being used for economic reasons, especially in the melting of cast iron in electric furnaces. The use of majority amounts of steel scrap in the charge, instead of pig iron necessitates modifying the chemical composition (increase of $\mathrm{C}$ and $\mathrm{Si}$ content), and improved metallurgical processes. The experimental melts with different ratio of raw materials were realized in laboratory conditions. The paper is aimed to investigate the effects of different composition of charge materials in relation to specific technological conditions of the microstructure, mechanical properties and performance of gray iron.
\end{abstract}

KEY WORDS: steel scrap; gray cast iron; synthetic gray iron; charge materials.

\section{Introduction}

In 2013, global production of castings increased to more than 103 million metric tons, an increase of $3.4 \%$ when compared to the previous year. This rate of growth is a slight bump up from 2012's 2.4\% boost.

Cast iron is still the most common casting alloy. Gray cast iron (GCI) is a broad class of ferrous casting alloys normally characterized by a microstructure of flake graphite in a ferrous matrix. It is essentially a $\mathrm{Fe}-\mathrm{C}-\mathrm{Si}$ alloy containing small quantities of other alloying elements, and the most widely used casting alloy with an annual production worldwide 47821690 metric tons in year 2013. World's No.1 GCI producer is Germany (2012; 5186722 metric tons). ${ }^{1,2)}$ Production of gray iron in Slovakia in 2012 was 27000 metric tons.

GCI is traditionally chosen in many industrial applications because of its use, good castability, low-cost (20-40\% less than steel) and wide range of achievable mechanical and technological properties and simple melting technique. The GCI manufacturing process can be carried out with the use of various charging materials. It can be based on pig iron with the returns and steel scrap additions. ${ }^{3-6)}$

The microstructure of GCI is characterized by graphite lamellas dispersed into the ferrous matrix. Foundry practice can influence nucleation and growth of graphite flakes, so that size and type enhance the desired properties. The amount of graphite and size, morphology and distribution of graphite lamellas are critical in determining the mechanical

\footnotetext{
* Corresponding author: E-mail: gabriel.fedorko@tuke.sk DOI: http://dx.doi.org/10.2355/isijinternational.ISIJINT-2016-270
}

behavior of GCI. ${ }^{7)}$

GCI is a multi-component alloy, which solidifies with eutectic microstructure. Depending on the cooling rate or solidification pattern, cast iron primarily solidifies according to the thermodynamically metastable system or the stable system. If the metastable path is followed, the rich carbon phase in the eutectic microstructure is iron carbide while if the stable solidification path is followed, the carbon rich phase is graphite. ${ }^{8)}$

The mechanical properties of GCI depend on the microstructure developed during solidification. Conventional GCI has a pearlite matrix and a tensile strength ranging from 140 to $400 \mathrm{MPa}^{9,10)}$

Inoculation causes significant improvements in mechanical properties because the microstructure of the alloy is modified. $^{11)}$

At present, from an economic perspective, it is therefore high priority in the field of GCI research to address the possibility of pig iron replacement in the charge by cheaper raw materials. The transition from traditional use of pig iron (claimed to be rich in nuclei) to synthetic GCI prepared from steel scrap (generally believed to contain only few graphitic nuclei) requires the regulation of chemical composition of metal. It is closely linked with the introduction of metallurgical silicon carbide $\mathrm{SiC}$ (as a siliconizing and carburizing additive). ${ }^{12,13)}$ The use of larger amounts of steel scrap (it is generally assumed to contain only a few seed crystals of graphite) in the charge instead of pig iron necessitates modifying the chemical composition of the melt (increasing the carbon and silicon content), and improvement of metallurgical processes.

Steel scrap is normally used in an amount of $10 \% \div 50 \%$. 
In order to lower the cost per charge a larger ratio of steel scrap is used, in particular deep-drawn sheet metal, which is very reliably and quickly carburized in the induction furnace. However, for the production of synthetic GCI, that is GCI produced from scrap steel, carburizing agents with low sulfur, nitrogen, ash and volatile matter content must be used. Using a large ratio of steel scrap increases a tendency to create a chilling and therefore requires very careful monitoring of the entire production process and control by means of cooling curves with knowledge of their evaluation by computing. ${ }^{9)}$ Polluted steel scrap, e.g. excessively rusted or dirty with oils and organic impurities, increases the hydrogen content in the liquid metal, metal loss by burnout, and the amount of slag. The sorting of steel scrap is very important, particularly regarding the alloying elements $(\mathrm{Cr}$, $\mathrm{Mn}, \mathrm{Ni}, \mathrm{Cu})$, and the undesirable metals $(\mathrm{Cu}, \mathrm{Pb}, \mathrm{Sn}, \mathrm{Zn})$, which during melting completely or partly enter into the liquid metal, or pollute the air. Carbon, silicon, manganese, sulphur and phosphorus are traditionaly regarded as five elements normally present in GCI. ${ }^{14)}$ Their effect on GCI properties is generally known. The use of steel scrap in the charge may lead to increased content of above-mentioned elements. Their effect on GCI properties was reported by authors. ${ }^{8,15)}$

The composition of the charge with a higher ratio of steel scrap may bring some metallurgical problems. The increasing ratio of steel scrap in the charge leads to an increased tendency to not only the formation of pearlite, but also a greater risk of shrinkage. Therefore, some car factories, which procure castings of braking parts, prescribe the ratio of pig iron in the charge above $20 \% .{ }^{16,17)}$

At present, the use of steel scrap in the charge is limited to $50 \%$ of the total charge weight. The main obstacle to the wide use of ferrous scrap in synthetic cast iron manufacturing is low effectiveness of known methods of iron and steel carburizing. ${ }^{18)}$

The aim of this paper was to determine, what is the maximum quantity of steel scrap in the charge for the production of gray cast iron acceptable without significant impairment of its properties, i.e. how does steel scrap in the charge influence the chemical composition, structure and mechanical properties of gray cast iron.

\section{Experimental Methods}

In the laboratory conditions 19 experimental meltings of cast iron with flake graphite were performed, while raw materials composition of the charge was changed in each individual melting. The charge weight was in each case 15 $\mathrm{kg}$, the charge was made up of steel scrap, foundry return GCI25 and steel pig iron. The chemical composition of the charge materials is shown in Table 1.

In addition to these three basic materials, there were also used ferrosilicon FeSi75 as an inoculant and pitch coke as a carburizing agent; silicon carbide $\mathrm{SiC} 50 \%$ was used as an inoculant and carburizer. The content of the additives was chosen so that the resulting chemical composition of the produced cast iron satisfied the criteria for GCI 25 according to EN 1561, Table 2. Table 3 shows the composition of metal bearing charge and the calculated amount of additives for individual meltings.
Table 1. Chemical composition of the charge raw materials.

\begin{tabular}{cccccc}
\hline \multirow{2}{*}{ Input material } & \multicolumn{5}{c}{ Chemical composition, \% } \\
\cline { 2 - 6 } & $\mathrm{C}$ & $\mathrm{Si}$ & $\mathrm{S}$ & $\mathrm{P}$ & $\mathrm{Mn}$ \\
\hline Steel scrap & 0.660 & 0.95 & 0.014 & 0.055 & 0.633 \\
Foundry returns GCI25 & 3.46 & 2.18 & 0.055 & 0.075 & 0.455 \\
Steel pig iron & 3.90 & 0.98 & 0.07 & 0.06 & 0.46 \\
\hline
\end{tabular}

Table 2. Chemical composition and properties of GCI 25 cast iron according to EN 1561.

\begin{tabular}{cccc}
\hline Chemical composition* & \multicolumn{3}{c}{ Mechanical properties } \\
\hline $\mathrm{C}, \%$ & $3.1-3.3$ & $\mathrm{Rm}, \mathrm{MPa}$ & $250-350$ \\
$\mathrm{Si}, \%$ & $1.7-1.9$ & $\mathrm{Rp} 0,1, \mathrm{MPa}$ & $165-228$ \\
$\mathrm{Mn}, \%$ & $0.8-1.0$ & $\mathrm{Rd}, \mathrm{MPa}$ & 840 \\
$\mathrm{P}_{\text {max. }} \%$ & 0.5 & $\mathrm{HBmax}$. & 240 \\
$\mathrm{~S}_{\text {max. }} \%$ & 0.15 & $\mathrm{Sc}$ & $0.87-0.93$ \\
Recommended wall thickness, mm & & $15-70$ \\
\multicolumn{2}{c}{ structure } & \multicolumn{3}{c}{ Pearlite + ferrite } \\
\hline
\end{tabular}

*The chemical composition is not standardized

Table 3. Composition of metal bearing charge and calculated quantities of additives for individual meltings.

\begin{tabular}{|c|c|c|c|c|c|c|}
\hline \multirow[b]{2}{*}{ m.no. } & \multicolumn{3}{|c|}{ The ratio of metal charge $[\%]$} & \multicolumn{3}{|c|}{ Additives $[\mathrm{kg}]$} \\
\hline & $\begin{array}{l}\text { Steel } \\
\text { scrap }\end{array}$ & $\begin{array}{c}\text { Foundry returns } \\
\text { GCI } 25\end{array}$ & $\begin{array}{l}\text { Steel pig } \\
\text { iron }\end{array}$ & Carburizer & $\mathrm{SiC}$ & FeSi75 \\
\hline 1. & - & 100 & - & - & - & 0.03 \\
\hline 2. & 20 & 50 & 30 & 0.064 & 0.096 & - \\
\hline 3. & 30 & 50 & 20 & 0.112 & 0.098 & - \\
\hline 4. & 50 & 30 & 20 & 0.205 & 0.173 & - \\
\hline 5. & 40 & 30 & 30 & 0.156 & 0.171 & - \\
\hline 6. & 100 & - & - & 0.440 & 0.285 & - \\
\hline 7. & 80 & 20 & - & 0.247 & 0.06 & 0.100 \\
\hline 8. & 100 & - & - & 0.440 & 0.075 & 0.140 \\
\hline 9. & 10 & 70 & 20 & 0.017 & 0.015 & 0.010 \\
\hline 10. & 20 & 70 & 10 & 0.065 & 0.015 & 0.010 \\
\hline 11. & 30 & 70 & - & 0.113 & 0.015 & 0.010 \\
\hline 12. & 30 & - & 70 & 0.108 & 0.069 & 0.117 \\
\hline 13. & 40 & 60 & - & 0.106 & 0.032 & 0.021 \\
\hline 14. & 40 & - & 60 & 0.155 & 0.070 & 0.140 \\
\hline 15. & 50 & 50 & - & 0.207 & 0.065 & 0.100 \\
\hline 16. & 50 & - & 50 & 0.203 & 0.065 & 0.220 \\
\hline 17. & 80 & 20 & - & 0.333 & 0.060 & 0.100 \\
\hline 18. & 80 & - & 20 & 0.333 & 0.073 & 0.140 \\
\hline 19. & 100 & - & - & 0.440 & 0.075 & 0.140 \\
\hline
\end{tabular}

The actual process of melting was carried out in an electric induction furnace ISTOL with capacity $40 \mathrm{~kg}$, melting performance $-150 \mathrm{~kg} . \mathrm{h}^{-1}$, the frequency $2000 \mathrm{~Hz}$. The furnace was lined with magnesia bricks. After melting, metal was overheated to $1420^{\circ} \mathrm{C}$.

In the first series of meltings (No. $1 \div 6$ ) different ratios 
of the three basic charge materials (iron, recycled material and steel scrap) were used. Only silicon carbide served as an inoculant, which was added to the last portions of input material and pitch coke was used as a carburizer. In a second series of meltings (No. 7, 8, 11, 13, 15, 17), only steel scrap and recycled material were used in the charge, in the meltings No. 12, 14, 16, and 18 only steel scrap and steel pig iron were used in the charge. Ferrosilicon was added in two portions, one half of the calculated amount was added during melting and the other half into a ladle during pouring of GCI. Silicon carbide was added at the beginning of melting, to ensure long-term inoculation effect.

From each melting a test bar (Fig. 1) was cast to determine the mechanical properties and for metallographic
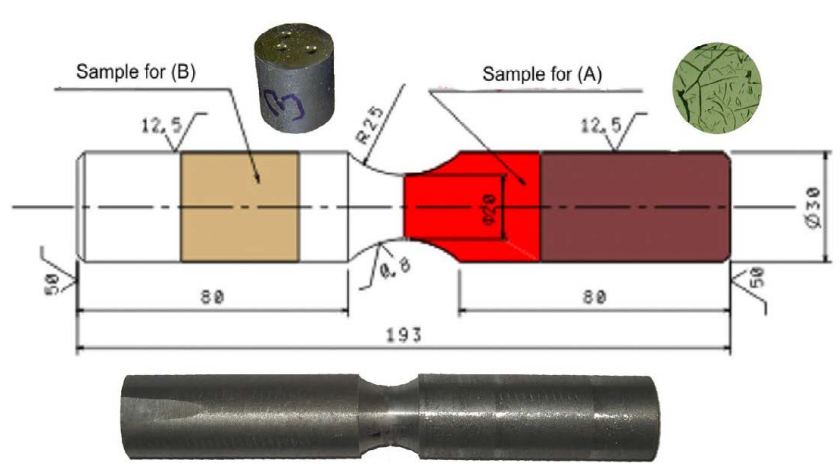

Fig. 1. The test bar for tensile strength test, indicating sampling for metallographic analysis (A) and hardness test (B). (Online version in color.) analysis.

The mechanical properties (tensile strength and hardness HB) were determined on the bars with a nominal diameter $\mathrm{d} 0=20 \mathrm{~mm}$ taken from precast diameter $\phi 30 \mathrm{~mm}(\mathrm{EN}$ 1561).

Tensile strength test was performed on the machine ZDM 30 from VEB Werkstoffprüfmaschinen - Leipzig and Brinell hardness test on tester HPO 3000 from VEB Werkstoffprüfmaschinen - Leipzig under conditions $10 / 3000 / 10$, i.e. $\phi 10$ $\mathrm{mm}$ diameter ball, load force $30000 \mathrm{~N}$, load time $10 \mathrm{~s}$.

Samples for metallographic analysis were taken from test bars, as indicated in Fig. 1. The samples were prepared by standard method. In non-etched condition, distribution and size of graphite was observed. Etching of the samples was done by Nital $2 \%$. On etched samples content of pearlite, and other structural components were observed.

\section{Results and Discussion}

Table 4 shows the chemical analyses of the different meltings, the carbon equivalent, the saturation degree and the values of basic mechanical properties (tensile strength and hardness) of metal samples from individual meltings.

Carbon and silicon are the two most important elements in gray iron; they have the greatest influence on mechanical properties, while the effect of carbon is predominant. They very strongly influence the graphitization. With increasing carbon and silicon content the degree of graphitization increases, which reflects in the deterioration of the mechani-

Table 4. Chemical composition, carbon equivalent, saturation degree, tensile strength and hardness of samples from individual meltings.

\begin{tabular}{|c|c|c|c|c|c|c|c|c|c|c|}
\hline \multirow{2}{*}{ m.no. } & \multirow{2}{*}{$\begin{array}{c}\text { Charge } \\
\text { Steel scrap (SC)/ } \\
\text { return material (RM)/ } \\
\text { pig iron (PI), } \%\end{array}$} & \multicolumn{5}{|c|}{ Chemical composition, $\%$} & \multirow{2}{*}{$\mathrm{CE}, \%$} & \multirow{2}{*}{ Sc } & \multirow{2}{*}{$\mathrm{Rm}, \mathrm{MPa}$} & \multirow{2}{*}{$\mathrm{HB}$} \\
\hline & & $\mathrm{C}$ & $\mathrm{Si}$ & S & $\mathrm{P}$ & $\mathrm{Mn}$ & & & & \\
\hline 1. & 0/100/0 & 3.23 & 2.74 & 0.016 & 0.031 & 0.41 & 4.12 & 0.93 & 360 & 245 \\
\hline 2. & $20 / 50 / 30$ & 3.39 & 1.53 & 0.046 & 0.110 & 0.33 & 3.88 & 0.914 & 320 & 246 \\
\hline 3. & $30 / 50 / 20$ & 2.93 & 1.85 & 0.041 & 0.140 & 0.8 & 3.53 & 0.81 & 381 & 257 \\
\hline 4. & $50 / 30 / 20$ & 3.23 & 1.86 & 0.015 & 0.029 & 0.43 & 4.10 & 0.967 & 561 & 422 \\
\hline 5. & $40 / 30 / 30$ & 3.21 & 1.25 & 0.038 & 0.090 & 0.38 & 3.61 & 0.843 & 428 & 300 \\
\hline 6. & $100 / 0 / 0$ & 2.91 & 1.96 & 0.034 & 0.044 & 0.37 & 3.51 & 0.807 & 681 & 465 \\
\hline 7. & $80 / 20 / 0$ & 3.31 & 1.89 & 0.036 & 0.048 & 0.37 & 4.19 & 0.913 & 252 & 291 \\
\hline 8. & $100 / 0 / 0$ & 3.36 & 1.78 & 0.031 & 0.090 & 0.24 & 4.22 & 0.922 & 259 & 202 \\
\hline 9. & $10 / 70 / 20$ & 3.30 & 1.88 & 0.112 & 0.064 & 0.24 & 4.20 & 0.92 & 257 & 187 \\
\hline 10. & $20 / 70 / 10$ & 3.21 & 1.90 & 0.126 & 0.061 & 0.24 & 4.22 & 0.897 & 253 & 190 \\
\hline 11. & $30 / 70 / 0$ & 3.32 & 1.75 & 0.126 & 0.062 & 0.21 & 4.11 & 0.917 & 255 & 161 \\
\hline 12. & $30 / 0 / 70$ & 3.54 & 1.82 & 0.122 & 0.063 & 0.29 & 4.40 & 0.982 & 251 & 188 \\
\hline 13. & $40 / 60 / 0$ & 3.40 & 1.90 & 0.122 & 0.061 & 0.38 & 3.99 & 0.949 & 262 & 186 \\
\hline 14. & $40 / 0 / 60$ & 3.28 & 1.79 & 0.143 & 0.061 & 0.23 & 4.24 & 0.91 & 263 & 180 \\
\hline 15. & $50 / 50 / 0$ & 3.33 & 1.82 & 0.109 & 0.060 & 0.19 & 4.09 & 0.923 & 270 & 201 \\
\hline 16. & $50 / 0 / 50$ & 3.48 & 1.93 & 0.056 & 0.065 & 0.18 & 4.08 & 0.969 & 257 & 184 \\
\hline 17. & $80 / 20 / 0$ & 3.39 & 1.98 & 0.054 & 0.065 & 0.22 & 4.00 & 0.941 & 261 & 182 \\
\hline 18. & $80 / 0 / 20$ & 3.35 & 1.86 & 0.063 & 0.065 & 0.24 & 4.03 & 0.927 & 288 & 210 \\
\hline 19. & $100 / 0 / 0$ & 3.39 & 1.77 & 0.064 & 0.068 & 0.34 & 4.04 & 0.931 & 279 & 202 \\
\hline
\end{tabular}


cal properties except for dynamic toughness and damping characteristics. With the decreasing carbon and silicon content, the values of strength increase and equalize in the individual parts of castings. The tensile strength of GCI depends on the wall thickness of the casting. With increasing thickness of the wall the decrease in tensile strength is the greater the higher the silicon content. This is caused by a feritization and thickening of graphite flakes. The silicon content in gray iron should not be higher than 3\%, because its higher content slows down graphitization and supports the formation of silicocarbides, which sharply reduces the plasticity of cast iron and deteriorates its fluidity. ${ }^{19)}$

The contents of carbon and silicon in different meltings as well as recommended ranges of these elements for LLG $25(3.1 \% \div 3.3 \% \mathrm{C}, 1.7 \% \div 1.9 \% \mathrm{Si})$ are shown in Figs. 2 and $\mathbf{3}$. The lower carbon contents than ones recommended by standard were detected only in two meltings - melting No. 3 and No. 6. Carbon contents higher by more than 0.1 wt.\% were found in the melting No. 12 and No. 16. These higher contents can be eliminated by reducing the amount of carburisers in the charge. Silicon contents lower than recommended by standard were detected in two meltings No. 2 and No. 5; only in meltings No. 1 and No. 4 they were significantly higher. The melting No. 1 consisted only of recycled material and as can be seen from chemical composition, the recycled material itself had higher silicon content $(2.74 \%)$.

One of the objectives of this paper is to study the influence of scrap content in the charge on the properties of cast iron. From this point of view are interesting the meltings No. 6, 8 and 19, where charge comprised only of scrap steel

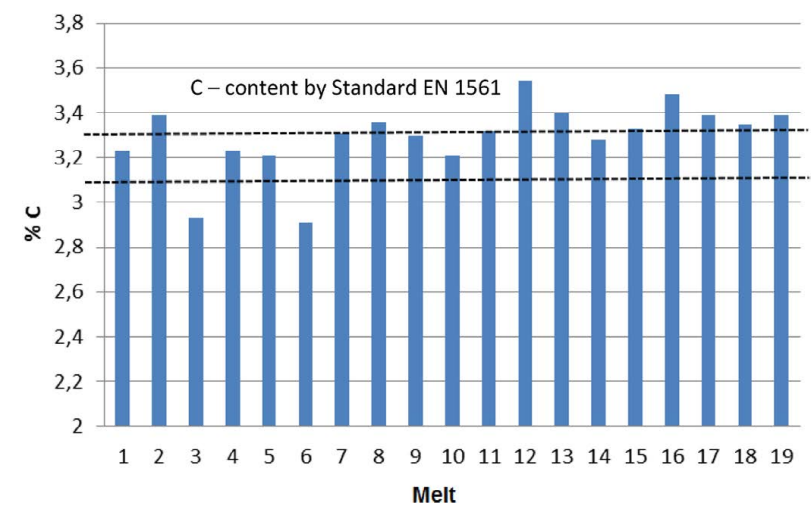

Fig. 2. The carbon content in individual meltings. (Online version in color.)

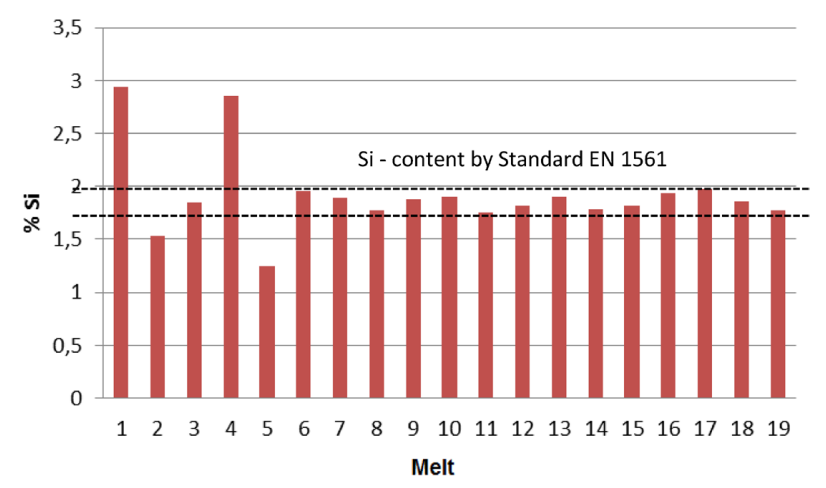

Fig. 3. The silicon content in individual meltings. (Online version in color.) and meltings No. 7, 17 and 18, where steel scrap made up $80 \%$ of the charge. In melting No. 6 the carbon content was lower than given in the standard, while in meltings No. 8 and No. 19, which also consisted solely of scrap steel, the carbon content complies with the standard. The charges in both meltings were identical also in terms of the additives carbon contents are very similar.

In the meltings No. 7, 17 and 18, where the scrap steel ratio in the charge was $80 \%$, the required carbon content was achieved in all meltings. The silicon contents are in accordance with the standard (or very slightly above the recommended value) in all meltings No. $6 \div 19$. The silicon content in meltings No. 8 and 19 (100\% scrap) was almost the same (1.78\% and $1.77 \%)$. The melting No. 6 also consisted only of scrap steel but unlike the earlier meltings, FeSi75 was not added into the charge, just $\mathrm{SiC}$ and that in greater amount than in the case of meltings No. 8 and 19 . The silicon contents in meltings No. 7, 17 and 18 where the charge contained $80 \%$ of scrap steel were in accordance with the standard.

The content of manganese in GCI 25 recommended by standard is $0.8 \% \div 1.0 \%$. None of the meltings did reach such levels of manganese content, whereas the manganese content in the charge materials itself was less almost by half. Manganese eliminates the impact of sulfur in gray iron, the sulfur content up to $0.12 \%$ is not considered harmful when counterbalanced by manganese. ${ }^{20)}$ Since the sulfur content in the individual meltings were much lower than those permitted in gray iron, it was not necessary to increase the content of manganese in meltings.

Since the contents of the various elements in the gray iron are only recommended, a guiding parameter that takes into account the chemical composition of cast iron but allows its different variations, is the saturation degree $(\mathrm{Sc})$ which is expressed by relation (1). ${ }^{21}$

$$
S_{C}=\frac{\% \mathrm{C}}{4.3-0.3(\% S i+\% P)} \text {. }
$$

According to the standard, the level of cast iron GCI 25 saturation degree should be between 0.87 and 0.93 . A significantly lower levels of saturation degree were found for meltings No. 3, 5 and 6, where there was either very low carbon or silicon content (below the values specified in the standard). A cast iron, in which either carbon or silicon content exceeds the norm, exhibits higher values of saturation degree.

Table 5 shows the results of metallographic analysis of individual meltings (ratio of pearlite in the sample, size of graphite flakes and their distribution). The size of graphite in samples from meltings No. $1 \div 5$ was in an interval of $60 \mu \mathrm{m} \div 120 \mu \mathrm{m}$. There was relatively small ratio of pearlite in the samples, the sample No. 2 (20 SC/50 RM/30 PI) actually contained only ferrite. The graphite distribution was interdendritic random orientation. Sample No. 6, which was made only from the steel scrap with carburizing agents, but has not been inoculated, had ledeburitic structure, so neither the structure nor mechanical properties corresponded to gray iron. In the meltings No. $2 \div 5$ graphite was segregated in the form of flakes, but the formed structure was very heterogeneous, being a mixture of transformed ledeburite, pearlite and secondary cementite. The structure of meltings No. $7 \div$ 
Table 5. Metallographic analysis of samples from individual meltings.

\begin{tabular}{|c|c|c|c|}
\hline $\begin{array}{l}\text { No. of } \\
\text { melting }\end{array}$ & $\begin{array}{c}\text { Ratio of } \\
\text { pearlite } \\
\text { in structure } \\
{[\%]}\end{array}$ & $\begin{array}{c}\text { Size of } \\
\text { graphite } \\
{[\mu \mathrm{m}]}\end{array}$ & Distribution of graphite flakes \\
\hline 1. & 20 & $60-120$ & $\mathrm{E}$ - interdendritic prefered orientation \\
\hline 2. & 0 & $60-120$ & $\mathrm{D}$ - interdendritic random orientation \\
\hline 3. & 45 & $60-120$ & $\mathrm{D}$ - interdendritic random orientation \\
\hline 4. & 45 & $60-120$ & $\mathrm{D}$ - interdendritic random orientation \\
\hline 5. & 70 & $60-120$ & $\mathrm{D}$ - interdendritic random orientation \\
\hline 6. & & & ledeburitic structure \\
\hline 7. & 92 & $30-60$ & $\mathrm{D}$ - interdendritic random orientation \\
\hline 8. & 85 & $120-250$ & A - uniform \\
\hline 9. & 96 & $120-250$ & A - uniform \\
\hline 10. & 96 & $250-500$ & A - uniform \\
\hline 11. & 96 & $120-250$ & A - uniform \\
\hline 12. & 85 & $120-250$ & A - uniform \\
\hline 13. & 85 & $120-250$ & A - uniform \\
\hline 14. & 96 & $120-250$ & A - uniform \\
\hline 15. & 85 & $120-250$ & A - uniform \\
\hline 16. & 85 & $120-250$ & A - uniform \\
\hline 17. & 96 & $60-250$ & $\mathrm{C}-$ mixed \\
\hline 18. & 96 & $250-500$ & $\mathrm{C}$-mixed \\
\hline 19. & 96 & $250-500$ & $\mathrm{C}$-mixed \\
\hline
\end{tabular}

19 was homogeneous compared to earlier meltings. The size of graphite flakes was $120 \mu \mathrm{m} \div 250 \mu \mathrm{m}$ and their distribution was uniform. The ratio of pearlite was above $80 \%$ in all samples. Samples from meltings No. $17 \div 19$ showed mixed distribution of flakes and ratio of pearlite was $96 \%$.

Figure 4 shows the distribution of the graphite in the sample No. 1, which charge was $100 \%$ recycled material, on the Fig. 5 is sample No. 6, the charge consisted of 100\% steel scrap, but ferrosilicon was not used as an inoculant, in Fig. 6 the structure of the sample No. $19(100 \%$ steel scrap charge + carburizer $+\mathrm{SiC}+\mathrm{FeSi75})$. The shape of the graphite and its distribution in the sample No. $18(80 \%$ steel scrap $+20 \%$ of steel making pig iron) is shown in Fig. 7. In all meltings with a higher ratio of steel scrap in the charge ( $50 \%$ or more) was achieved either homogeneous or mixed distribution of graphite flakes, graphite flakes size was $120 \mu \mathrm{m} \div 500 \mu \mathrm{m}$ and lamellar pearlite ratio was more than $85 \%$.

The prescribed range of tensile strength for cast iron GCI 25 according to the standard is 250 to $350 \mathrm{MPa}$ and maximum hardness HB 240. None of the meltings without inoculation (meltings No. $1 \div 6$ ) except for the melt No. 2 (20\% steel scrap, $50 \%$ return material and $30 \%$ pig iron) have met the strength criteria. High values of Rm and HB for the melting No. 6 indicate that this material is closer to steel than cast iron (ledeburitic steel). On the other hand, all meltings from melting No. 7 and higher meet the strength and hardness criteria of the standard.

By using of software STATISTICA 7 the analyse of influence of charge materials (steel scrap - $z$, return mate-

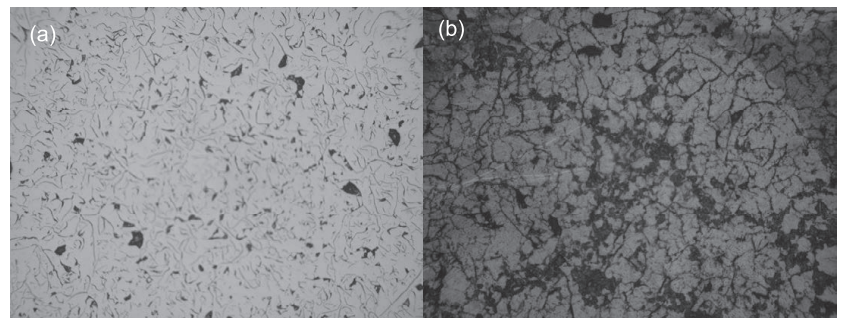

(a) unetched, mag. 100x

(b) etched by Nital $2 \%$, mag. 100x

Fig. 4. The structure of GCI (melting No. 1).

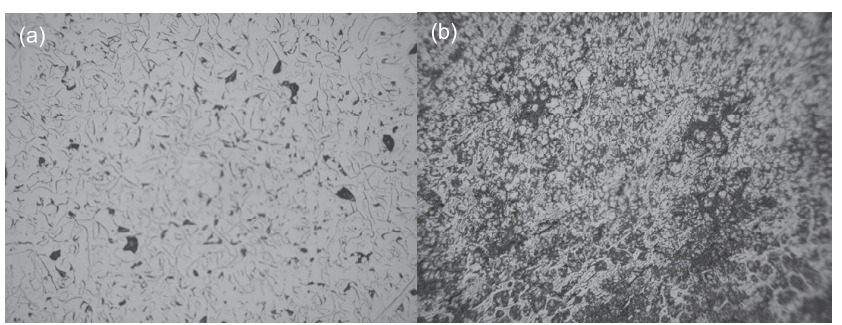

(a) unetched, mag. 100x

(b) etched by Nital $2 \%$, mag. $100 x$

Fig. 5. The structure of GCI (melting No. 6).

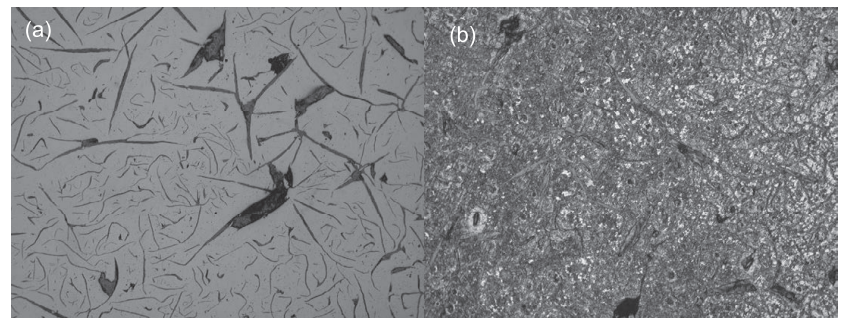

(a) unetched, mag. 100x

(b) etched by Nital $2 \%$, mag. $100 x$

Fig. 6. The structure of GCI (melting No. 19).

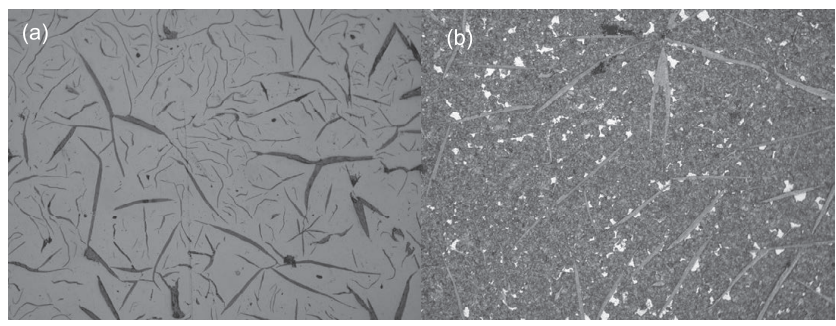

(a) unetched, mag. 100x

(b) etched by Nital $2 \%$, mag. $100 \mathrm{x}$

Fig. 7. The structure of GCI (melting No. 18).

rial $-\mathrm{y}$, pig iron - $\mathrm{x}$ ) on tensile strength $(\mathrm{Rm})$ and hardness (HB) was made and regression equations were calculated. As follows from the analysis, the greatest impact on the resulting mechanical properties (tensile strength $\mathrm{Rm}$ and hardness HB) has a steels scrap. It follows from the gradient of plane in thernary diagram and from coefficient by variable ,,$Z^{\prime \prime}$ in regresion equation - in Fig. 8 for tensile strength (Rm) and in Fig. 9 for hardness (HB). As shown in Fig. 10 the increase in the ratio of steel scrap in the charge does not reduce strength of cast iron. Increasing its content caused a moderate increase in tensile strength, Fig. 10. The effect of steel scrap in the charge on hardness is similar. The objective in the production of cast iron is to reach maximum required strength without exceeding the recommended hardness. This requirement was achieved in all meltings from No. 7 through No. 19. These melts were made by equal 


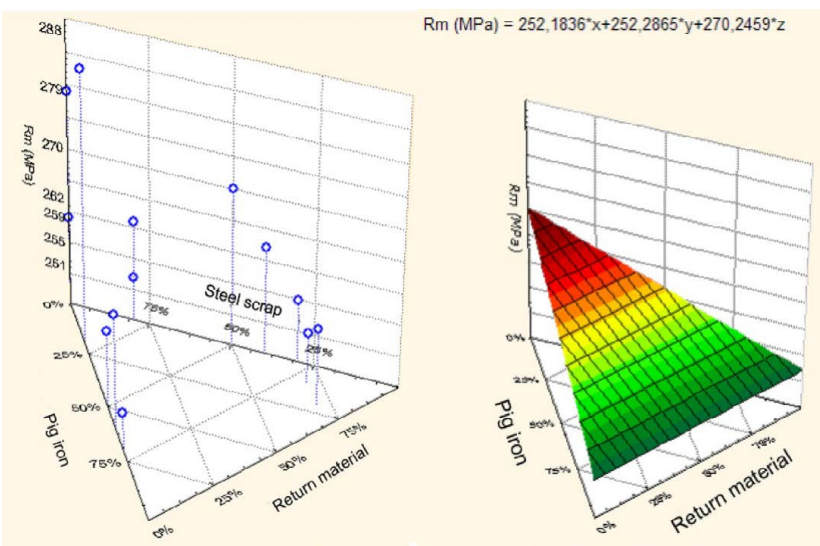

Fig. 8. Ternary diagram of charge raw materials influence on tensile strength Rm. (Online version in color.)

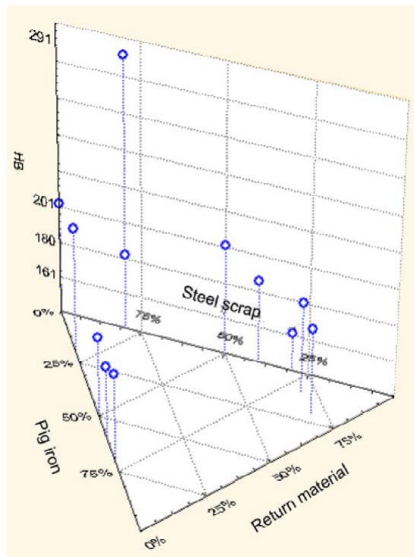

$H B=165,0772^{*} x+175,8877^{*} y+218,4685^{x} z$

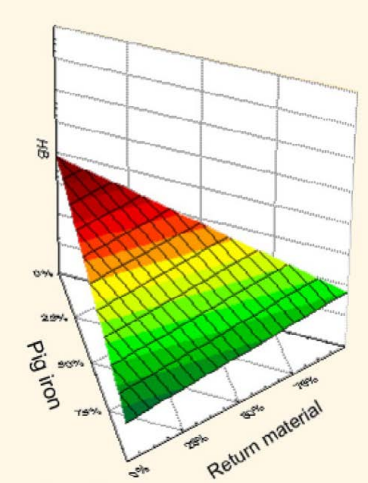

Fig. 9. Ternary diagram of charge raw materials influence on hardness HB. (Online version in color.)

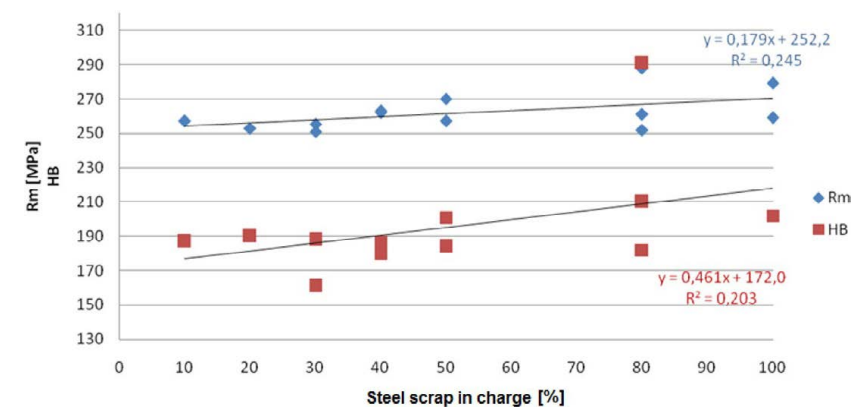

Fig. 10. The effect of the ratio of steel scrap in the charge on the mechanical properties. (Online version in color.)

conditions (they were preinoculated with $\mathrm{SiC}$ and they were inoculated secondary with FeSi75.

\section{Conclusions}

The objective of this paper was to determine the influence of the steel scrap content in the charge during the manufacture of GCI on its properties, and whether synthetic GCI i.e. GCI made only of steel scrap shall comply with the requirements of the standard for given type of cast iron. The GCI 25 was selected as a target with the recommended chemical composition, pearlitic - ferritic structure, degree of eutecticity $0.87 \div 0.93$, prescribed tensile strength of $250 \mathrm{MPa} \div 350$ $\mathrm{MPa}$ and a maximum hardness HB 240.
From obtained results, follow these conclusions:

- In the manufacture of synthetic GCI it is possible to achieve the recommended levels of silicon and carbon by precisely calculated amount of carburiser and properly conducted carburization and inoculation of cast iron.

- Chemical composition of synthetic GCI, corresponding to given type of cast iron EN - GJL 250 is only an orientation and affects the saturation degree, which is obligatory for given cast iron. Also, synthetic gray iron and gray iron produced with a high percentage of scrap steel $(80 \%$ and $50 \%$ ) achieved through proper carburization and inoculation the saturation degree required by standard.

- The structure of GCI (graphite shape and distribution, ratio of pearlite) was not negatively affected by high steel scrap content in the charge.

- The mechanical properties of synthetic GCI, its tensile strength and hardness HB, are in accordance with the standard. Based on obtained results, we can say that an increasing ratio of steel scrap in the charge led to a slight increase in strength, but also to an increase in hardness, while still not exceeding the hardness value required by the standard. Even with high ratios of steel scrap in the charge, hardness was well below the standard permissible value.

- The increase of steel scrap ratio in the charge alone will not result in optimum mechanical properties and structure of GCI. The proper metallurgical treatment of melt, that is correct temperature of overheating, standing time, melt temperature at inoculation, the amount of inoculant, or pre-inoculation using $\mathrm{SiC}$ is essential.

\section{Acknowledgement}

This work is a part of these projects VEGA 1/0258/14, VEGA 1/0063/16, VEGA 1/0703/16, VEGA 1/0073/17, KEGA 006STU-4/2015, KEGA 018TUKE-4/2016, APVV15-0247.

\section{REFERENCES}

1) W. Wang, T. Jing, Y. Gao, G. Qiao and X. Zhao: J. Mater. Process. Technol., 182 (2007), 593.

2) W. Xu, M. Ferry and Y. Wang: Mater. Sci. Eng. A., 390 (2005), 326.

3) MCDP: Modern Cast., (2014), December, 17.

4) D. Bartocha, J. Gawronski and K. Janerka: Arch. Foundry, 3 (2003), 22 .

5) D. Bartocha and K. Janerka: Arch. Foundry, 5 (2005), 17.

6) K. Janerka, D. Bartocha, J. Szajnar and J. Jezierski: Arch. Metall. Mater., 55 (2010),851.

7) D. Bartocha, K. Janerka and J. Suchon: J. Mater. Process. Technol., 162-163 (2005), 465.

8) R. Schneidewind and R. G. McEiwee: AFS Trans., 58 (1950), 312.

9) H. T. Angus: Cast Iron: Physical and Engineering Properties. Vol. 1, 2nd Ed., Butterworths, (1976).

10) S. O. Seidu and I. O. Ogunniyi: Mater. Res., 16 (2013), 145.

11) A. Vasko: Arch. Foundry Eng., 10 (2010), 93.

12) A. Vasko: Transf. inovácií, 22 (2012), 183.

13) H. R. Abbasi, M. Bazdar and A. Halvaee: Mater. Sci. Eng. A., 444 (2007), 314.

14) S. Seidu: J. Metall. Eng., 3 (2014), 92

15) P. Futas and A. Pribulova: Proc. Evaluation of People and Products Features, University of Maribor, Maribor, (2014), 99.

16) J. R. Davis: Cast Irons, ed. by J. R. Davis, ASM International, OH, (1996).

17) C. F. Walton: Gray and Ductile Iron Castings Handbook, Iron Founder's Society, Cleveland, (1971).

18) W. Łybacki: Mechanika, 5 (2005), 62.

19) O. M. Suarez and C. R. Loper, Jr.: AFS Trans., 010 (2001), 1.

20) G. M. Goodrich, T. G. Oakwood and R. B. Gundlach: AFS Trans., 072 (2003), 1

21) C. E. Bates: AFS Trans., 50 (1984), 923. 